\title{
REPRESENTASI POLA PERILAKU TASAWUF DALAM MEMBANGUN DINAMISASI MASYARAKAT GLOBAL
}

\author{
Muhammad Natsir \\ bilfanasir@gmail.com \\ Universitas Islam Nahdlatul Ulama (UNISNU) Jepara
}

DOI: $10.21580 /$ wa.v6i1.3021

\begin{abstract}
Islam Rahmatan lil 'alamin religion that teaches attitude wasathiyah accordance with the methodology of the Qur'an, that is gentle, courteous, friendly, diledang chest, and rely on the power of prayer. The face of Islamic archipelago brought by the Sufi sage mujahid is very strongly colored by the style of Sufism, ie the pattern of keIslaman gentle, polite and tolerant. The Ulama 'from time to time others have positioned themselves as the torch of the Ummah, who constantly guides the people into a beautiful tree. The root of firm beliefs; stems, branches, twigs and leaves are istiqomah; while the fruit of Islamic trees is the integrity of morals, ethics, and morals. Islamic teachings have three pillars; faith, Islam and ihsan, then developed into aqidah, shari'ah, and morals or tawhid, fiqh and mysticism. Ihsan is the essence of Sufism and vice versa, both of which are the main pillars for building a pious Muslim personality, a person who is reflected in the self and behavior of Prophet Muhammad as the living Qur'an. Indonesia has entered the 21st century or the global century, many Muslim societies have succeeded in occupying strategic positions in all spheres of life; political, economic, social and cultural rights, which should color Indonesia with Islamic values such as work ethic, productivity, professional, and integrity that lead to the benefit of mankind. However, their morality is dirty because it shows only the symbols of Islam. Ihsan (Sufism) is understood inclusively; confined to the domain of religious behavior only, so that Rekontekstualisasi the values of Sufism on the entire realm of human life will be a manifest behavior as a representation of the value of the teachings of Sufism itself to realize the maslahah for human dynamic as the times.
\end{abstract}

Keywords: Representation, Sufism, society, global 


\begin{abstract}
Abstrak
Islam agama Rahmatan lil 'alamin yang mengajarkan sikap wasathiyah sesuai dengan metodologi Al-Qur'an, yaitu lembut, santun, ramah, berlapang dada, dan mengandalkan kekuatan doa. Wajah Islam Nusantara yang dibawa oleh para mujahid sufi wali sanga adalah sangat kental diwarnai oleh corak Tasawuf, yaitu corak keIslaman yang lembut, santun dan toleran. Para Ulama' dari kurun waktu ke waktu yang lain telah memposisikan dirinya sebagai obor umat, yang senantiasa membimbing umat agar menjadi sebatang pohon yang indah. Akar keyakinan yang kokoh; batang, dahan, ranting dan dedaunannya adalah istiqomah; sedangkan buah pohon keIslaman adalah integritas akhlak, etika, dan moral. Ajaran Islam memiliki tiga pilar; iman, Islam dan ihsan, kemudian berkembang menjadi akidah, syari'ah, dan akhlak atau tawhid, fikih dan Tasawuf. Ihsan merupakan essensi Tasawuf dan sebaliknya, keduanya merupakan pilar utama untuk membangun pribadi Muslim yang saleh, yaitu pribadi yang tercermin pada diri dan perilaku Nabi Muhammad SAW sebagai Al-Qur'an hidup. Indonesia telah masuk pada abad ke-21 atau abad global, banyak masyarakat muslim yang berhasil menduduki posisi strategis di segala ranah kehidupan; politik, ekonomi, sosial dan budaya, yang seharusnya mewarnai Indonesia dengan nilai-nilai keIslaman semisal etos kerja, produktifitas, professional, dan integritas yang berujung pada kemaslahatan umat manusia. Akan tetapi, moralitas mereka kotor karena hanya menunjukkan simbol-simbol keIslaman saja. Ihsan (Tasawuf) dipahami secara inklusif; terbatas pada ranah perilaku peribadatan saja, sehingga Rekontekstualisasi nilai-nilai Tasawuf pada seluruh ranah kehidupan manusia akan menjadi wujud perilaku nyata sebagai representasi dari nilai ajaran tasawuf itu sendiri untuk mewujudkan maslahah bagi manusia yang dinamis seiring perkembangan zaman.
\end{abstract}

Kata Kunci : Representasi, Tasawuf, masyarakat, global

\title{
A. Pendahuluan
}

Islam masuk ke Nusantara yang dibawa oleh mujahid wali sanga bersamaan dengan masa maraknya Tasawuf abad pertengahan dan pertumbuhan tarekat, merujuk pada sosok Al-Ghazali sebagai ulama pelopor konsep Tasawuf moderat yang diterima oleh kalangan fuqoha $(111 \mathrm{M})$. Diantara para tokoh sufi yang mewarnai corak Tasawuf di Indonesia, diantaranya; Muhyiddin Ibnu Al-'arabi ( 1246 M), Abdul Qadir Jailani (w. 1166), Abu alNajib al-Suhrawardi (w. 1167), Najmuddin al-Kubro (w. 1221), dan Abu Hasan al-Syaili (w. 1258). Dan salah satu faktor yang mempermudah penetrasi Islam di Nusantara adalah pengaruh ajaran kosmologi dan metafisis Tasawuf Ibn al-'Arabi dengan konsepnya insan kamil yang dapat dipadukan dengan ide-ide kosmolofi india dan ide kosmologi pribumi, sebagai legitimasi religius, dan ini berpotensi bagi para raja untuk meneguhkan sistem 
feodal, semisal di kesultanan Buton Sulawesi Tenggara yang memanfaatkan emanasi Ilahiah martabat tujuh sebagai penejalasan atas adanya masyarakat yang berjenjang dalam kasta Hindu. ${ }^{1}$

Agama Islam memiliki 3 pilar ajaran; Akidah, Syari'ah, dan Tasawwuf yang telah dirumuskan dalam istilah Iman, Islam, dan Ihsan. Ketiga pilar ini harus kokoh dalam diri seorang muslim dalam menjalani kehidupannya, keyakinan yang kokoh, ibadah ritual keagamaan yang istiqomah, dan integritas akhlak, etika dan moral yang menuntun perilaku hidupnya. Ketiga pilar Islam ini harus seimbang dan proporsional dalam diri manusia, sehingga akan mencerminkan perilaku agamis, lembut santun dan toleran (pribadi mubsin).

Agama Islam menjadi agama bagi mayoritas penduduk di Indonesia, menjadi agama yang dominan karena mayoritas penduduk Indonesia adalah kaum muslimin dan bahkan negeri Indonesia ini merupakan negeri dengan penduduk Muslim tebesar di dunia. Islam dan kaum muslimin memiliki eran dan berkontribusi paling besar dalam mendirikan Indonesia. Kontribusi pada perjuangan fisik dalam mengusir penjajah dan juga dalam meletakkan negara persatuan dan kesatuan Indonesia.

Pada Abad 21 atau disebut dengan abad global, muncul fenomena masyarakat muslim telah banyak yang telah berhasil menduduki posisi strategis di lembaga eksekutif, legislatif, dan yudikatif, serta beberapa lembaga swasta nasional yang seharusnya mereka mengembangkan perjuangan para pendahulu, mewarnai Indonesia dengan nilai-nilai keIslaman seperti etos kerja, produktifitas, professional, dan integritas yang bermuara pada upaya mewujudkan keadilan dan kesejahteraan sosial bagi seluruh, tetapi ironisnya justru mereka mengalami krisis identitas dan krisis integritas. Secara formal mereka menampilkan simbol-simbol keIslaman, tetapi moralitas mereka busuk. Mereka menjadi virus dan mengncam ketahanan moral bangsa ini.

Tasawuf atau mengimplementasikan Ihsan merupakan modal spiritual dalam Islam yang dapat didayagunakan untuk membangun manusia dan peradaban. Manusia yang senantiasa berbuat baik dan menebarkan kemaslahatan bagi seluruh makhluk di alam kosmos. Manusia yang selalu berjuang membangun integritas dan solidaritas untuk memuliakan manusia dan kemanusiaan. Manusia yang selalu menjunjung tinggi nilai-nilai maslahah; menjaga agama, jiwa, harta, harga diri, dan menjaga akal. ${ }^{2}$

Perilaku Tasawuf dipahami tidak sebatas pada ritual keagamaan saja; ibadah sholat dan dzikir serta perilaku tertentu (tarekat). Akan tetapi, dapat diaktualisasikan dan dikontekstualkan pada setiap gerak aktifitas manusia, baik berupa aktifitas ritual keagamaan, sosial dan pada ranah kegiatan ekonomi manusia di manapun mereka berada. Hal ini cerminan dari hadits Nabi SAW yang artinya:"hendaknya kamu menghambakan diri kepada Allah seakan akan kamu melihatNya, dan jika kamu tidak melihatNya maka sesungguhnya Dia melihatmu”. Dan hadits lain yang artinya:"termasuk Islam yang baik bagi seseorang adalah dia meninggalkan segala sesuatu yang tidak ada manfaatnya

${ }^{1}$ Wildan Imaduddin Muhammad, "Transformasi tasawwuf dan Identitas Islam nusantara" dalam Proceeding Islam Nusantara (LP3.Universitas Malang Press, 2015), 355

2 Abdul rahman al-nahlawy, Ushul al-tarbiyah al-Islamiyah wa asalibiha (Damaskus: Dar al-fikr, 1996), 69 
(merugikan diri dan orang lain)". Dari hadits yang pertama menanamkan sifat muroqobah atau merasa diawasi oleh Allah SWT sehingga manusia mengontrol diri untuk tidak berbuat kejelekan dan kerusakan dan berusaha berbuat baik. Dan hadits yang kedua menanamkan sifat peduli dan membangun spirit untuk selalu berbuat sesuatu yang memberikan kemaslahatan bagi diri dan orang lain serta berusaha meminimalisir segala perbuatan yang dapat merugikan orang lain baik dari ucapan, perilaku, dan kebiasaan. Selanjutnya tulisan artikel ini akan menjawab dua permasalahan penting, yaitu; 1) Bagaimana prinsip dan Tujuan bertasawuf ?. 2) Bagaimana Pola perilaku Tasawuf di zaman global ?

\section{B. Pembahasan}

\section{Masarakat Global}

Dalam perjalanan - peradaban - manusia sekarang ini, masyarakat dapat dikelompokkan ke dalam tiga bagian. Pertama masyarakat pertanian (agricultural society); aktifitas ekonominya bersandar pada sumber alam, kedua masyarakat industri (industrial society);aktifitas ekonominya bersandar pada peralatan produksi dan mesin pengolah, dan ketiga masyarakat informasi (informatical society); aktifitas ekonominya bersandar pada perkembangan teknologi elektronik dan informasi.

Revolusi teknologi menimbulkan evolusi ekonomi, gaya hidup, pola pikir dan sistem rujukan yang berbeda dengan yang terjadi pada masyarakat agrikultural dan industri. Dalam kaitan ini terdapat tiga keadaan dalam mensikapi revolusi industri, yaitu kelompok yang optimis, pesimis, dan pertengahan antara keduanya. Dan dari sikap mental yang demikian itu, kehadiran ilmu pengetahuan dan teknologi telah melahirkan sejumlah problematika masyarakat modern, diantaranya adalah;

a) Disintegrasi ilmu pengetahuan

b) Kepribadian yang terpecah (split personality)

c) Penyalahgunaan Iptek

d) Pendangkalan Iman

e) Pola hubungan materialistik

f) Menghalalkan segala cara

g) Stres dan Frustasi

h) Kehilangan harga diri dan masa depan ${ }^{3}$

Dari fenomena yang muncul dalam kehidupan manusia sekarang, perlu kiranya ada upaya reorientasi, dan reaktualisasi nilai dan ajaran agama melalui proses internalisasi yang gradual dan berkelanjutan dengan melakukan aktifitas, rutinas, dan tradisi keagamaan yang dapat mengantarkan manusia mampu memahami makna hidup dan kehidupan, sehingga menjadi pribadi Muhsin yang mampu beradaptasi dengan kemajuan peradaban dan menjadi bagian dari komunitas masyarakat yang dinamis dalam menghadapi tantangan laju perkembangan zaman.

\footnotetext{
${ }^{3}$ Abuddin Nata, Akblak tasawuf dan Karakter Mulia (Jakarta: RajaGrafindo Persada, 2013), 247-253.
} 


\section{Tasawuf}

Dari segi bahasa terdapat banyak kata dan istilah yang dihubungkan para ahli untuk menjelaskan kata Tasawuf. Terdapat lima istilah yang berkenaan dengan Tasawuf, yaitu; alsuffah (orang yang berpindah dengan Nabi SAW dari Makkah ke madinah), saff (barisan), sufi (suci), shopos (yunani: hikmat), dan suf (kain wol). ${ }^{4}$

Tasawuf atau sufism (mysticalIslam), yaitu kata benda verbal yang berati perilaku atau proses menjadi sufi. Penambahan ism bukan bermakna suatu "ism" atau teori, tapi lebih cenderung sebagai pengalaman hidup dan pencarian menuju kesempurnaan. ${ }^{5}$

Tasawuf dari kata shaff berarti barisan, karena kebiasaan para sufi memilih barisan pertama dalam shalat berjama'ah di masjid dan keberhasilan mereka membangun barisan persaudaraan spiritual, sehingga satu sama lain di antara mereka saling memanggil dengan panggilan ikhwan, yang berarti saudara. Tasawuf berasal dari kata shafwah yang berarti pilihan, karena para sufi dianggap sebagai umat pilihan, karena kesucian jiwa dan kedekatannya dengan Allah SWT sehingga sufi memiliki kekuatan spiritual (spiritual power) untuk menjalani hidup dengan tulus, bersahabat dengan ikhlas dan berkarya dengan produktif. Mereka menjadi tauladan umat, bahkan menjadi guru masyarakat.

Tasawuf berasal dari kata shuffah yang berarti tempat duduk yang terbuat dari batu atau kayu. Hal ini menghubungkan dengan ahl-Shuffah, yaitu para sahabat yang menempati salah satu pojok masjid Nabawi yang tidak memiliki harta dan keluarga, tekun beribadah, hidup sederhana, tidur di atas Shuffah supaya tidak nyenyak kemudian bangun malam untuk melakukan sholat tahajud.

Dari segi praktis operasional, Imam nawawi al-Bantani menyebutkan dalam sya'ir tentang makna Tasawuf yang berbunyi:

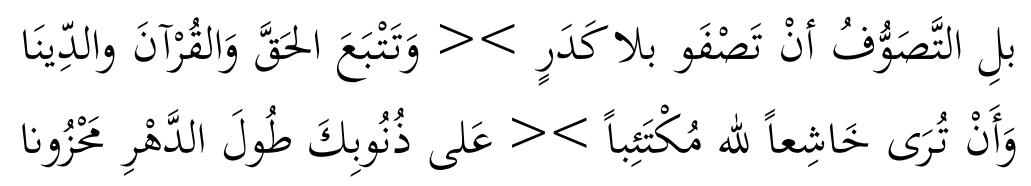

"Tasawuf adalah kamu suci tanpa noda keruh \# kamu mengikuti kebenaran, al-Qur'an dan agama”.

"Dan hendaknya kau terlihat Khusyuk kepada Allah dalam keadaan bersedih

hati \# atas dosa-dosamu, sepanjang masa dalam keadaan takut khawatir".

Bersedih hati dan takut serta khawatir dapat dipahami khawatir terjerumus dosa yang dapat menyebabkan jauh dari rahmat, ridho dan ampunan Allah SWT, sehingga para sufi termotivasi untuk mendekatkan diri dan berbuat yang benar lagi maslahah sehingga mereka akan meraih ampunan, ridho dan rahmat Allah swt di dunia sampai akhirat. ${ }^{6}$

Selanjutnya Imam Nawawi menjelaskan bahwa ada tiga istilah yang saling bersinergi dan berkaitan yaitu syari'at, tariqoh dan hakekat yang ketiganya menjadi pilar

\footnotetext{
${ }^{4}$ Harun Nasution, Falsafah dan Mistisisme dalam Islam (Jakarta: Bulan Bintang, 1983), 56-57).

${ }^{5}$ Moh. Ulumuddin, "Syari'ah dan Tasawuf Lokal" dalam Jurnal At-Tahdzib (Vol.1, edisi Januari-Juli, 2013), 5

${ }^{6}$ Nawawi al-Bantani al-Jawi, Maroqi al-Ubudiyah (Surabaya: al-hidayah, 2010), 5
} 
penopang dalam berTasawuf, Imam al-Showy memaparkan bahwa syari'at adalah beberapa hukum yang dibebankan oleh Rasululloh SAW kepada kita berupa hal yang wajib, sunnah, haram, makruh dan boleh, juga mengambil agama Allah swt dengan melaksanakan kewajiban dan menjauhi larangan. Tariqoh adalah melaksanakan kewajiban dan kesunahan, meninggalkan hal yang dilarang, melepaskan diri dari sifat berlebihan pada sesuatu yang diperbolehkan, dan berhati-hati dalam segala hal seperti bersifat Wira'i, melatih mental untuk selalu beribadah di malam hari, dan berpuasa. Hakekat adalah memahami hakekat (essensi) dari segala hal seperti menyaksikan nama dan sifat, menyaksikan dzat Allah swt, menyaksikan rahasia al-Qur'an, rahasia larangan dan hal yang diperbolehkan, dan ilmu bersifat gaib yang diperoleh tanpa seorang pengajar, dan dipahami dari Allah SWT, seperti yang termaktub dalam surat al-anfal: 29 dan dalam surat al-baqoroh ayat 282, yang berbunyi :

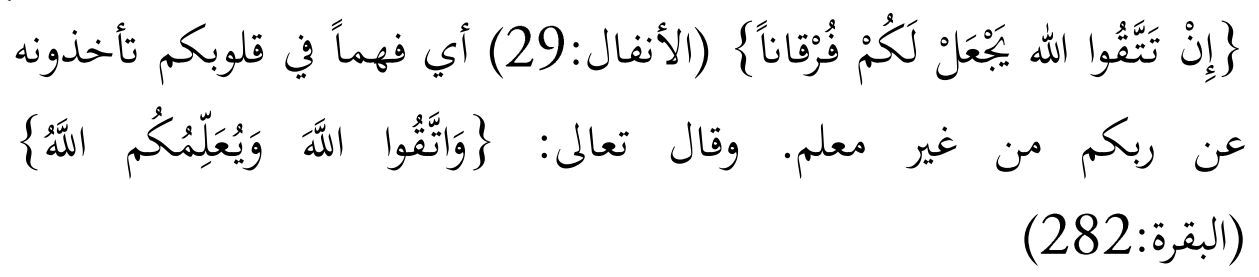

"Hai orang-orang beriman, jika kamu bertaqwa kepada Allah, Kami akan memberikan kepadamu Furqaan.7 (QS. Al-Anfal 29) dan Kami akan jaubkan dirimu dari kesalahan-kesalahanmu, dan mengampuni (dosa-dosa)mu. dan Allah mempunyai karunia yang besar." ".............................dan bertakwalah kepada Allah; Allah mengajarmu; dan Allah Maha mengetahui segala sesuatu." (QS. Al-Baqarah: 282(

Ketiga pilar agama Islam; syari'at, tariqoh, dan hakekat inilah yang akan menjadikan manusia menjadi hamba-hamba Allah yang muhsinin.

Dari segi linguistik Tasawuf dapat dipahami sebagai bentuk sikap mental yang selalu memelihara kesucian diri, beribadah, hidup sederhana, rela berkorban untuk kebaikan dan selalu bersikap bijaksana. Sikap jiwa seperti itu pada hakikatnya adalah akhlak yang mulia. Tasawuf pada intinya adalah upaya melatih jiwa dengan berbagai kegiatan yang dapat membebaskan dirinya dari pengaruh kehidupan dunia, sehingga tercermin akhlak yang mulia dan dekat dengan Allah SWT. Dengan ringkas kata, Essensi atau hakikat Tasawuf adalah bidang kegiatan yang berhubungan dengan pembinaan mental rohaniah agar selalu dekat dengan Tuhan.

\section{Tujuan Ber'Tasawuf}

Tasawuf muncul karena tidak puas terhadap syari'at. Sebab syari'at hanya menyentuh satu dimensi hidup beragama, yaitu eksoteris (lahiriah) semata. Sedang hidup

7 Petunjuk yang dapat membedakan antara yang haq dan yang batil, dapat juga diartikan disini sebagai pertolongan. 
beragama mencakup dimensi lahiriah dan batiniyah (esoteris). Dimensi esoteris dalam Islam adalah Tasawuf. ${ }^{8}$

Adapun tujuan Tasawuf secara garis besar meliputi :

1. Tasawuf yang bertujuan untuk pembinaan aspek moral dangan berbagai aktifitas jiwa yang berkeseimbangan, penguasaan dan pengendalian hawa nafsu sehingga memiliki komitmen dan konsistensi haya kepada keluhuran moral. Tasawuf yang bertujuan moralitas ini pada umumnya bersifat praktis dan biasa disebut Tasawuf Akhlaki.

2. Tasawuf yang bertujuan ma'rifatulloh melalui pengungkapan langsung atau kasyf. Tasawuf jenis ini bersifat teoritis dengan seperangkat norma dan nilai yang diformulasikan secara analitis-sistematis dan dikenal dengan Tasawuf Irfani.

Tasawuf yang bertujuan memperoleh pengetahuan tentang hakikat hubungan alam manusia dengan tuhan, Tasawuf jenis ini biasa dikenal Tasawuf Falsafi.?

\section{Periodesasi Tasawwuf}

Sejak dekade akhir abad II Hijriah, sufisme sudah popular di kalangan masyarakat di kawasan dunia Islam, sebagai perkembangan lanjutan dari gaya keberagaman para zahid dan '́bid, kesalehan yang mengelompok di serambi mesjid Madinah. Fase awal ini juga disebut sebagai fase asketisme yang merupakan bibit awal tumbuhnya sufisme dalam peradaban Islam. Fase asketisme ini setidaknya berlangsung sampai akhir abad II Hijriah, dan memasuki abad ke III sudah menampakkan adanya peralihan dari asketisme ke sufisme. Fase ini dapat disebut sebagai fase kedua, yang ditandai oleh pergantian sebutan zahid menjadi sufi. Pada kurun waktu ini percakapan para zahid sudah meningkat pada persoalan bagaimana jiwa yang bersih itu, apa itu moralitas dan bagaimana pembinaannya serta perbincangan masalah kerohanian lainnya. Kemudian muncul berbagai konsepsi tentang jenjang perjalanan yang harus ditempuh seorang sufi (al-maqamat) serta cir-ciri yang dimiliki oleh seorang salik (calon sufi) pada tingkatan tertentu (al-ahwal). Demikian juga pada periode ini sudah mulai berkembang perbincangan tentang pada derajat fana dan ittihad. Bersamaan dengan itu, tampillah para penulis Tasawuf terkemuka, seperti alMuhasibi (w.234 H), al-Harraj (w. 277H) dan al-Junaid al-Baghdadi (w. 297H), dan penulis lainnya. Secara konseptual-tekstual lahirnya sufisme barulah pada periode ini, Sejak kurun waktu itu sufisme berkembang terus ke arah penyempurnaan dan spesifikasi terminology seperti konsep intuisi, dzauq dan al-kasyf.

${ }^{8}$ Sudirman Tebba, Tasawuf Positif (Kencana: Bogor, 2003), 137-138

9 Masyharuddin, Pemberontakan Tasawuf, kritik Ibn Taimiyah atas rancang Bangun Tasawuf (Surabaya: ,2007), 227-228 


\section{Sufi Orthodoks}

Sejak abad ketiga hijriah sudah mulai popular sebutan sufisme ortodoks, yang dirintis oleh Harits al-Muhasibi seperti telah disebutkan terdahulu sebagai tandingan bagi sufisme popular yang didukung sepenuhnya oleh kaum Syi'ah. Tujuan sufisme ortodoks adalah ihya atsar al-salaf reaktualisasi paham salafiyah dengan mengupayakan tegaknya kembali warisan kesalehan sufi terdahulu yakni para sahabat dan generasi sesudahnya dengan tetap mempraktekkan kehidupan yang bersifat lahiriah. abad ke-3 ditengarai oleh sebutan Sufisme ortodoks sebagai gerakan pertama dalam pembaharuan sufisme. Dalam pandangan sufisme ortodoks penyimpangan berat yang dilakukan oleh sufisme Syi'i adalah dalam aspek tauhid atau teologi. karena itu, tema sentral dari pembaharuan sufisme ini adalah rekonsiliasi antara teologi sufisme dengan teologi ortodoks yakni teologi Ablusunnah wal jama'ah. Salah satu rumusan teologinya ialah Islam adalah pengetahuan yang bersifat apriori dan simplisiter iman adalah pengetahuan tentang Tuhan, tentang ketuhanannya yang bertempat di qalbu (hati), ma'rifat adalah pengetahuan sejati tentang Tuhan yang berpusat dalam fuad (pusat hati), dan pengakuan tentang ke-Esaan Tuhan dengan sifatsifatnya adalah pengetahuan tentang kesatuannya (unitasnya) yang mutlak dan tempatnya adalah sirrr (inti qalbu). Usaha rekonsiliasi yang dirintis oleh al-Muhasibi dilanjutkan oleh al-Kharraj dan al-Junaid dengan tawaran konsep-konsep Tasawuf yang kompromistis antara sufisme dengan kelompok ortodoks (kaum salafiyah). Tujuan gerakan ini adalah untuk menjembatani dan bila dapat untuk mengintegrasikan antara kesadaran mistik dengan syari'at Islam. Jasa mereka yang paling berharga adalah lahirnya doktrin al-baqa (subsistensi) sebagai imbangan dan legalitas al-fana.

Gerakan sufisme ortodoks mencapai puncaknya pada abad lima hijriah melalui tokoh monumental al-Ghazali (w.503H). gerakan ini bertujuan untuk membendung invasi berkembangnya teologi sufisme yang menurut pandangan kaum ortodoks dapat merusak sendi-sendi ketauhidan, maka al-Ghazali merumuskan suatu konsepsi yang diharapkan dapat menampung aspirasi kedua belah pihak. Al-Ghazali menampilkan doktrin alma'rifat. Dia bermaksud dengan istilah ini adalah, pengetahuan yang diperoleh melalui penjelajahan batin atau eksperimen batin, yang secara tegas dipertentang-kan dengan pengetahuan intelektual seperti teologi dialektis. Konsepsi ini menentang perumusan teologi yang dilakukan secara rasional-dialektik.

\section{Sufisme-Theosofi}

Pengalaman kesufian yang menurut al-Ghazali tidak mungkin diungkapkan menerobos juga lewat konsepsi Ibn Arabi (w.638H). corak ma'rifat yang dikembangkan tokoh popular dari Murcia ini, tidak sejalan dengan konsepsi ma;rifat sebelumnya. Ia bukan saja mengungkapkan kasatuan manusia dengan Tuhan seperti halnya dengan Abu Yazid al-Bistami tetapi ia menyodorkan satu bentuk olahan esoterik yang mirip dengan filsafat. Ia berusaha mencerahkan hubungan antara fenomena alam yang pluralistik dengan Tuhan sebagai prinsip keesaan yang melandasinya. Berangkat dari pendapat sufisme bahwa yang mutlak hanya Allah, ia lalu mengatakan bahwa alam ini adalah (mazhar) dari asma 
dan sifat Allah, yang sebenarnya adalah zat-Nya. Yang Mutlak itu merupakan diri dalam citra keterbatasan yang empiris yang kemudian popular dengan doktrin wahdah al-wujud.

Paham baru ini menimbulkan ketegangan dan pertentangan yang lebih tajam dan meliputi segenap pemikiran Islam, karena paham ini dikategorikan sebagai pantheisme (paham serba Tuhan) yang tidak bisa disesuaikan dengan akidah Islam. Karena konsepsinya yang dinilai sementara sufi sangat ekstrim menuduhnya sudah keluar dari Islam (kafir). Fase ini sudah memasuki fase keempat yang ditandai masuknya unsur-unsur filsafat ke dalam sufisme, baik yang bersifat metodologis maupun yang mengambil postulat-postulat filsafat Yunani terutama neo-Platonisme. Agaknya persoalan ini pulalah yang melatarbelakangi terutama gerakan Ibn Taymiyah dan Ibn Qayyim pada abad kedelapan Hijriyah untuk melanjutkan usaha yang pernah dilakukan al-Ghazali. Ibn Taymiyah juga mengakui validitas metode eksperimen batin sufisme (ma'rifat), tetapi kualitas keabsahan itu baru relevan dengan syari'at. Rumusan ini secara tegas menolak doktrin monism (wahdah al-wujud) Ibn 'Arabi dan sekaligus juga menolak berbagai praktek ritual sufisme. Demikianlah telah terlihat bahwa masa kejayaan sufisme cukup lama dan tersebar di seantero dunia Islam. Namun memasuki abad kedelapan Hijriyah nampaknya sufisme telah memasuki masa kemandegan. Karena sejak masa itu tidak ada lagi konseo-konsep sufisme yang baru dan orisinil. Yang berjalan terus hanyalah sekedar ulasan-ulasan terhadap karya lama. Praktek pengamalan sufisme berjalan semarak tetapi lebih didominasi tarekat sebagai lembaga sufisme dan lebih menampakkan aspek ritusnya, bukan pada aspek substansinya.

\section{Neo-Sufisme}

Dalam segi penamaan, neo-sufisme adalah istilah yang baru berkembang pada abad dua puluh, yang dipopulerkan oleh Fazlur Rahman. Namun, hakekatnya gagasan neosufisme dalam sejarahnya telah ada sejak abad ke delapan Hijiriyah, yaitu suatu corak Tasawuf yang terintegrasi dengan syari'ah, dan adalah Ibn Taymiyyah (w.728H), sebagai pencetus gagasan yang selanjutnya diteruskan oleh muridnya Ibn Qayyim. Kebangkitan kembali sufisme di dunia Islam dengan sebutan neo-sufisme, nampaknya tidak bisa dipisahkan dari kebangkitan agama sebagai penolakan kepercayaan yang berlebihan kepada sains dan teknologi yang notabene merupakan produk modernism. Modernism dinilai telah gagal memberikan kehidupan yang bermakna bagi manusia, karenanya upaya kembali ke agama dianggap sebagai solusi paling tepat sebagai jalan pemaknaan terhadap kehidupan secara universal. ${ }^{10}$

\section{Tasawuf Kontemporer (Fenomena Tasawuf Nusantara)}

Tasawuf kontemporer dapat dicermati melalui fenomena Tasawuf yang berlangsung, ada dua hal yang dapat kita cermati dari fenomena ini, yaitu;

${ }^{10}$ Zuherni AB,"Sejarah Perkembangan Tasawuf" dalam Jurnal Substantia (Vol. 13. No. 2. 2011), $250-255$ 
50 | Representasi Pola Perilaku Tasawuf ....

1- Gerakan Tasawuf.

2- Gagasan Tasawuf yang tertuang dalam buku tentang Tasawuf dan sufi.

\section{Gerakan Tasawuf}

Gerakan dapat kita lihat adanya Jama'ah Thoriqoh Mu'tabaraoh al-nahdhiyyah (JATMAN) sebagai organisasi otonom NU yang memiliki kiprah yang sentral dalam masyarakat abad 21, organisasi yang dipangku oleh Habib Muhammad Luthfi bin Ali bin Yahya dari Pekalongan, Mursyid tariqah Syadziliyah, Qadariyah wa Naqsyabandiyah, dan Naqsyabandiyah al-khalidiyah.

Agenda terakhir yang dilakukan oleh JATMAN adalah melaksanakan konferensi internasional ulama' tariqah di Pekalongan dengan tema "Bela Negara: Islam" pada tanggal 15-17 Januari 2016. Dan dihadiri oleh Habib Luthfi bin Yahya (Indonesia), Syekh Adnan (siria), syekh Muhammad fadhil (cicit syekh Abdul Qadir al-Jailani), Habib Zaid bin Abdurraohman bin Yahya (yaman), shaykh Aziz idrisi (Maroko), shaykh Aziz Abidin 'Aun al-Qaddoumi dan shaykh Umar Hadhrah (yaman). Konferensi selama tiga hari di Hotel Santika Pekalongan menghasilkan sembilan butir, yaitu;

a) Negara adalah tempat tinggal untuk mengimplementasikan agama dalam kehidupan.

b) Bernegara merupakan kebutuhan primer dan tanpanya kemaslahatan tidak terwujud.

c) Bela negara adalah di mana setiap warga merasa memiliki dan cinta terhadap negara sehingga berusaha untuk mempertahankan dan memajukannya.

d) Bela negara merupakan suatu kewajiban seluruh elemen bangsa sebagaimana dijelaskan al-Qur'an dan Hadits.

e) Bela negara dimulai dari membentuk kesadaran diri yang bersifat ruhani dengan bimbingan para ulama'.

f) Bela negara tidak terbatas melindungi negara dari musuh atau sekedar tugas kemiliteran, melainkan usaha ketahanan dan kemajuan dalam semua aspek kehidupan seperti ekonomi, pendidikan, politik, pertanian, sosial budaya dan teknologi informasi.

g) Bela negara menolak adanya terorisme, radikalisme dan ekstrimisme yang mengatasnamakan agama.

h) Untuk mewujudkan bela negara dibutuhkan empat pilar, yaitu ilmuwan, pemerintahan yang kuat, ekonomi dan media.

i) Menjadi indonesia sebagai inisiator bela negara yang merupakan perwujudan dari Islam rahmatan lil 'alamin.

\section{Gagasan Tasawuf}

Mengenai gagasan Tasawuf dapat dilihat dari beberapa gagasan yang disampaikan oleh tiga tokoh sufi kontemporer Nusantara, yaitu Said Agil Siradj, Haidar Bagir, dan 
Nasarudin Umar. Ketiga tokoh ini memiliki kiprah yang besar dalam kancah kajian Tasawuf nasional dan internasional.

\section{Said Agil Siradj}

Ketua PBNU periode 2015-2020, guru besar bidang Tasawuf. Menurut beliau, sufi nusantara sejak aman dahulu merupakan tokoh-tokoh pembangunan peradaban yang impresif dan kongkrit. Tasawuf yang diemban oleh guru sufi nusantara telah menjad tsaurah al-ruhiya, yakni revolusi spiritual yang hasilnya bisa dinikmati secara nyata oleh generasi setelahnya. (siradj, 2013: 217). Tasawuf tidak berkaitan langsung dengan akhlak, maupun ilmu hikmah. Tasawuf adalah ilmu maqomat al-Qulub wa ahwaluha, yaitu ilmu yang memberikan jalan agar hati atau ruhani memiliki martabat/maqom/status. Dalam konsep Tasawuf ada tujuh maqom yang harus dilalui olah salik (orang yang menempuh jalan sufi): taubat, wara', zuhud, sabar, faqr, tawakkal, ridha, mahabbah dan makrifat. Ketujuh martabat tersebut dibagi menjadi tiga tingkatan kelompok, yakni 1) takhalli (membersihkan hati dari sifat tercela dan cinta dunia) 2) tahalli (pengisian hati dengan sabar, faqr, tawakkal, dan ridha), 3) tajalli (kebahagiaan sejati: mahabbah dan makrifat). ${ }^{11}$

Takhalli membersihkan dan Mensucikan hati dari akhlak tercela yang meliputi;
a) Rakus pada makanan
b) Rakus pada berbicara
c) Sifat marah
d) Dengki iri hati
e) Bakhil dan cinta dunia
f) Kegilaan dan cinta pangkat
g) Mencintai dunia
h) Sombong
i) bangga diri
j) riya' atau memperlihatkan amal baik

Tahalli menghiasi diri dan mengisi hati dengan melakukan akhlak-akhlak yang terpuji, diantaranya adalah;
a) Sikap taubat
b) Rasa takut kepada Allah
c) Sikap zuhud
d) Sifat sabar
e) Bersyukur
f) Ikhlas dan jujur
g) Bertawakkal
h) Cinta kepada Allah
i) Rela dengan ketentuan allah

${ }^{11}$ Said Agil Siradj, Dialog Tasawuf Kiai said: Akidah, Tasawuf, dan relasi Antar umat Beragama (Surabaya: Khalista, 2012), 45 
j) Mengingat kematian dan hakekatnya.

Tajalli (kebahagiaan sejati: mahabbah dan makrifat); mahabbah merupakan perilaku dan sikap mental yang dilandasi rasa cinta dalam setiap beribadah kepada Allah swt, tidak merasa terbebani dalam beribadah dan tidak mengharap pahala juga tidak karena takut neraka dalam beribadah kepada Allah swt. Makrifat merupakan sikap mental dan jiwa yang sudah mampu memahami essensi atau hakekat dari rahasia (hikmah) dari semua amalan ibadah yang dilakukan dan dari menjauhi larangan atau perbuatan dosa yang telah ditinggalkan. Atau dengan kata lain seseorang sudah merasakan kenikmatan dan keasyikan dalam beribadah kepada allah swt, dan hal ini berbeda-beda dari satu individu dangan individu yang lain sesuai dengan pengalaman spiritual masing-masing melalui latihan/pembiasan dan beberapa percobaan dari ritual keagamaan yang dilakukan.

\section{Haidar Bagir}

Doktor dalam kajian filsafat Islam tentang mulla sudra. Dalam spiritualnya beliau menemukan keindahan agama lewat Tasawuf. Beliau mengkaji pemikiran ibn al-“Arabi tentang agama cinta, saat ini ia perjuangkan lewat gerakan Islam cinta (GIC). Tasawuf menurut beliau adalah mengembangkan dan mengaktualisasikan potensi akhlak ke-Ilahian yang ada dalam diri manusia dalam kehidupan aktualnya, proses menuju hidup berakhlak dengan akhlak Allah. Berakhlak dengan akhlak Allah identik dengan menanamkan Asma dan sifatNya di dalam diri. ${ }^{12}$

\section{Nasarudin Umar}

Guru besar tafsir al-Qur'an yang mendalami kajian gender al-Qur'an di kanada. Menjelaskan tentang makna al-kitab dalam ayat al-Qur'an adalah hal penting untuk diuraikan. Menurut Nasarudin Umar, kata al-kitab dalam ayat al-Qur'an dalam perspektif sufi meliputi tiga bentuk, yakni makrokosmos (al-'alam al-kabir), mikrokosmos (al-'alam al-saghir), dan wahyu yang dibukukan (al-Qur'an). Perintah membaca dalam QS al-'alaq pada ayat pertama, dalam perspektif sufi adalah perintah yang lebih mengarah pada perintah untuk membaca alam raya. Dalam QS al-baqoroh: 02, kata al-kitab dalam ayat tersebut merujuk pada al-kitab dalam bentuk makrokosmos. Al-kitab juga ada bentuk mikrokosmos, yaitu diri manusia. Sebagaimana dalam QS ali-imron: 45. Hal ini karena dalam diri manusia tesimpul semua unsur makrokosmos. Bentuk ketiga dari makna al-kitab adalah al-Qur'an itu sendiri. ${ }^{13}$

\section{Kesimpulan}

Tiga pilar dalam agama Islam; iman, Islam dan ihsan inila yang mendasari kehidupan manusia, kemudian tiga hal tersebut berkembang menjadi akidah, syari'ah, dan

${ }^{12}$ Bagir, Semesta Cinta: Pengantar Kepada Pemikiran Ibn Arabi (Bandung: Mizan, 2015), 155

13 Umar, N, Tasawuf Modern: Jalan Mengenal dan mendekatkan Diri Kepada Allah (Jakarta: Republika, 2012), 102 
akhlak atau tawhid, fikih dan Tasawuf. Ihsan merupakan essensi Tasawuf dan sebaliknya, keduanya merupakan pilar utama untuk membangun pribadi Muslim yang saleh, yaitu pribadi yang tercermin pada diri dan perilaku Nabi Muhammad SAW sebagai Al-Qur'an hidup.

Hakikat Tasawuf adalah bidang kegiatan yang berhubungan dengan pembinaan mental rohaniah agar selalu dekat dengan Tuhan. Adapun tujuan Tasawuf secara garis besar yaitu;

1) Tasawuf Akhlaki: Tasawuf yang bertujuan untuk pembinaan aspek moral dangan berbagai aktifitas jiwa yang berkeseimbangan, penguasaan dan pengendalian hawa nafsu sehingga memiliki komitmen dan konsistensi haya kepada keluhuran moral. Tasawuf yang bertujuan moralitas ini pada umumnya bersifat praktis.

2) Tasawuf Irfani: Tasawuf yang bertujuan ma'rifatulloh melalui pengungkapan langsung atau kasyf. Tasawuf jenis ini bersifat teoritis dengan seperangkat norma dan nilai yang diformulasikan secara analitis-sistematis.

3) Tasawuf Falsafi: Tasawuf yang bertujuan memperoleh pengetahuan tentang hakikat hubungan alam manusia dengan Tuhan.

Dalam perkembangannya, representasi pola perilaku Tasawuf kontemporer dapat dicermati melalui fenomena Tasawuf yang berkembang, yaitu;

1) Gerakan Tasawuf dengan berupa maraknya Jama'ah majlis thoriqoh

2) Gagasan Tasawuf yang tertuang dalam buku tentang Tasawuf dan sufi.

Bentuk -bentuk perilaku tasawuf kontemporer yang berkembang merupakan bagian dari ritual keagamaan yang bertujuan untuk mengamalkan Iman, Islam, dan Ihsan dan mensinergikan antara perilaku perbuatan akal, jiwa dan hati agar tercipta keseimbangan pada diri manusia dan nuansa sistem kehidupan yang mengelilinginya. Pola-pola perilaku yang bernuansa tasawuf sebagai bagian dari bentuk representasi nilai ajaran tasawuf yang dikembangkan oleh masyarakat modern adalah bertujuan untuk menciptakan dinamisasi kehidupan manusia dan laju perkembangan zaman, sehingga kehidupan manusia, masyarakat dan komunitas di sekelilingnya menjadi sinergi, harmoni dan dinamis.

\section{Daftar Pustaka}

Bagir, H. 2015. Semesta Cinta: Pengantar Kepada Pemikiran Ibn Arabi. Mizan: Bandung Imam Nawawi al-Bantani al-Jawi. Tt. Maroqi al-Ubudiyah. Al-Hidayah: Surabaya Masyharuddin. 2007. Pemberontakan Tasawuf ( Kritik Ibn Taimiyah atas Rancang Bangun Tasawuf). Surabaya

Moh. Ulumuddin. Syari'ah dan Tasawuf Lokal. At-Tahdzib. Vol. No.1. 2013

Nasution Harun. 1983. Falsafah dan Mistisisme dalam Islam. Bulan Bintang: Jakarta

Nata, Abudin. 2013. Akhlak Tasawuf dan Karakter Mulia. RajaGrafindo: Jakarta

QuranInword. 2002

Rahman, Abdul al-nahlawy. 1996. Ushul al-tarbiyah al-Islamiyah wa asalibiha. Damaskus: Dar al-fikr 
54 $\mid$ Representasi Pola Perilaku Tasawuf ....

siradj, Agil. 2012. Dialog Tasawuf Kiai Said: Akidah, Tasawuf dan Relasi Antar umat Beragama. Khalista dan LTN PBNU: Surabaya

Siradj, Agil. 2013. Islam Kalap dan Islam karib. Daulat Press: Jakarta

Tebba, Sudirman. 2003. Tasawuf Positif. Kencana: Bogor

Umar, N. 2012. Tasawuf Modern: Jalan Mengenal dan Mendekatkan Diri kepada Allah. Republika: Jakarta

Wildan Imaduddin Muhammad. "Transformasi tasawwuf dan Identitas Islam nusantara". LP3UM. 2015

Zuherni AB. Sejarah Perkembangan Tasawuf. Substantia. Vol. 13. No. 2. 201 